\title{
Prospective study of the yield of physical examination compared with chest radiography in penetrating thoracic trauma
}

\author{
S R Thomson, W K J Huizinga, A Hirshberg
}

\begin{abstract}
A prospective study was conducted on 102 patients ( 84 male), with a median age of 27 years, who had sustained a penetrating chest wound to evaluate the ability of physical examination in comparison with chest radiography to determine management of these injuries. Knife wounds accounted for $92 \%$ of the injuries. Fifty three patients had a small collection of air or fluid in their pleural cavity that was not drained. Fifty six hemithoraces had a large collection of fluid or air and were treated by tube thoracostomy. Physical examination at presentation detected large collections of air and fluid correctly and predicted appropriate management (sensitivity 96\%, specificity 94\%). Residual collections of air or fluid or both were also predicted correctly by clinical examination. Seven small collections increased in size and required intubation. Routine pre-extubation radiographs were found to be of little value in management and their routine use is not recommended. Four patients required late thoracotomy for decortication. By using a policy of selective intubation, frequent clinical reassessment, and chest radiography when relevant, experienced trauma surgeons can manage most penetrating pleural injuries with an acceptably low complication rate.
\end{abstract}

The chest radiograph is considered the cornerstone of management in penetrating pleural injuries. The ease with which radiographs are obtained in trauma centres has led surgeons to rely on radiological evaluation of the chest for all management decisions. Although there is general agreement that a chest radiograph should be carried out at admission, the need for subsequent radiographs and their optimum frequency and timing is not known. At King Edward VIII Hospital, where over 1200 patients with penetrating chest trauma are admitted each year, we have queried the necessity of frequent routine chest radiographs in the management of these injuries. It is also important to know the reliability of physical examination in these circumstances because in the field and in hospitals with inadequate emergency radiological facilities management

decisions have to be made on clinical grounds alone. We have tried to answer this question in a prospective study.

\section{Methods}

All patients with penetrating pleural injuries (excluding trauma to the heart and great vessels) admitted to one of the six surgical units at King Edward VIII Hospital, Durban, from 1 May to 31 October 1987 were included in the study.

\section{MANAGEMENT POLICY}

The decision to institute intercostal drainage is normally based on criteria obtained from an erect inspiratory posteroanterior chest radiograph. ${ }^{1}$ A pneumothorax more than $2 \mathrm{~cm}$ in width from the chest wall at any point and/or an effusion extending above the angle of the 7th rib ("large collections") is drained. Smaller collections of air or fluid or both ("small collections") are not drained provided that the patient is symptomless. Patients with severe respiratory distress, mediastinal shift, or shock presumed to be due to a large haemothorax or tension pneumothorax are intubated before having a chest radiograph if $50 \mathrm{ml}$ of blood or air is freely aspirated by syringe.

Intercostal tube drainage was performed by introducing a 32 Malecot catheter by a trocar and cannula technique through the 5 th intercostal space in the mid axillary line under local anaesthesia. The catheter was connected to an underwater seal drainage system. The drain was removed when fluid drainage ceased or when the normal respiratory excursion of the fluid level in the underwater seal system had stopped. All patients with a large collection had a chest radiograph taken immediately before and after removal of the drain; those with a small collection had a chest radiograph on the morning after admission. Subsequent management was based on these radiographic findings according to the criteria for pleural intubation outlined above.

All patients were requested to attend for review within two weeks of discharge, when a chest radiograph was obtained.

\section{STUDY DESIGN}

On admission and before all further radiography the patients were examined by a senior surgical registrar or consultant experienced in the management of trauma. Pulse rate, blood pressurre, and respiratory rate were recorded. The chest wounds were inspected and pal- 
pated, the position of the trachea and cardiac apex beat was assessed for evidence of mediastinal shift, and chest percussion and auscultation were performed. Percussion was noted as giving normal, resonant or dull sounds and breath sounds as normal, decreased, or absent for each quadrant of the chest anteriorly and posteriorly. The findings were recorded on a proforma separate from the patient's notes.

On the basis of the physical findings the examiner predicted the presence, size, and nature of any pleural collection, and suggested appropriate management. The actual diagnosis and management decisions that were carried out were made independently by another member of the team and were based on the radiological assessment of the chest. For each patient requiring chest intubation the examiner's predictions were compared with the radiological diagnosis and management decisions at admission and before and after removal of the drain. When an intercostal drain was inserted before chest radiography the efflux from the drain was used to confirm or refute the validity of the presumptive diagnosis. The findings in patients with a small air or fluid collection on admission were compared with the findings after 24 hours by means of a relational data base program (D-Base III Plus, Ashton-Tate, Torrance, California).

\section{Results}

\section{PATIENTS AND INJURIES}

The study group consisted of 102 patients with penetrating chest injuries (84 male, 18 female; median age 27, range 14-60 years). The offending weapon was a sharp implement (usually a knife) in 91 cases, a low velocity handgun in eight, and a shotgun in three. Fifty three patients had small collections and 49 had large collections of air or fluid. Seventeen patients had bilateral injuries, and in five the pleural collection was on the side opposite to the obvious injury. We have assessed each hemithorax separately (204 hemithoraces).

Eighty five hemithoraces had no radiological abnormality. Sixty three hemithoraces with a small air and or fluid collection needed observation only. Fifty six hemithoraces required intercostal drainage in accordance with our management policy. Seven patients with a

Table 1 Diagnostic and management accuracy of physical examination in penetrating pleural injuries

\begin{tabular}{|c|c|c|c|c|c|}
\hline \multirow{2}{*}{$\begin{array}{l}\text { Radiological } \\
\text { diagnosis }\end{array}$} & \multirow[b]{2}{*}{ No } & \multicolumn{2}{|c|}{ Clinical diagnosis } & \multicolumn{2}{|c|}{ Management prediction ${ }^{\star}$} \\
\hline & & Correct & Incorrect & Correct & Incorrect \\
\hline $\begin{array}{l}\text { Large collections } \\
\text { Haemothorax } \\
\text { Pneumothorax } \\
\text { Haemopneumothorax }\end{array}$ & $\begin{array}{l}14 \\
19 \\
23\end{array}$ & $\begin{array}{l}13 \\
18 \\
16\end{array}$ & $\begin{array}{l}1 \\
1 \\
7\end{array}$ & $\begin{array}{l}13 \\
18 \\
23\end{array}$ & $\begin{array}{l}1 \\
1 \\
0\end{array}$ \\
\hline $\begin{array}{l}\text { Small collections } \\
\text { Haemothorax } \\
\text { Pneumothorax } \\
\text { Haemopneumothorax }\end{array}$ & $\begin{array}{l}13 \\
29 \\
21\end{array}$ & $\begin{array}{r}7 \\
22 \\
7\end{array}$ & $\begin{array}{r}6 \\
7 \\
14\end{array}$ & $\begin{array}{l}11 \\
25 \\
18\end{array}$ & $\begin{array}{l}2 \\
4 \\
3\end{array}$ \\
\hline Clear & 85 & 80 & 5 & 85 & 0 \\
\hline Total & 204 & 163 & 41 & 193 & 11 \\
\hline
\end{tabular}

ॠBased on a policy of selective intubation of large collections (see text).
Table 2 Comparison of the clinical prediction based on physical examination with the radiographically based decision

\begin{tabular}{lcc}
\hline & \multicolumn{2}{c}{ Management predicted from } \\
\cline { 2 - 3 } & $\begin{array}{ll}\text { chest } \\
\text { radiograph }\end{array}$ & $\begin{array}{l}\text { physical } \\
\text { examination }\end{array}$ \\
\hline Requires drain & 56 & 63 \\
No drain & 148 & 141 \\
Total & 204 & 204 \\
\hline
\end{tabular}

Sensitivity of physical examination $96 \%$

Specificity of physical examination $94 \%$

Predictive value of a positive result $86 \%$

Predictive value of a negative result $98 \%$

large air or fluid collection required immediate pleural intubation without prior chest radiography. In these patients the presence of a large collection was confirmed by the drainage of more than 1 litre of air or fluid.

\section{INITIAL ASSESSMENT}

Table 1 compares the clinical diagnosis and predicted management with the radiological diagnosis. A large intrapleural collection of air or blood was diagnosed accurately in 31 of 33 hemithoraces. In seven of the 23 large haemopneumothoraces, however, the effusion was missed, though the predicted management (intercostal drainage) was correct. Only seven of the 21 small haemopneumothoraces were diagnosed accurately. Nevertheless, the predicted management (table 2) was almost always correct (sensitivity $96 \%$, specificity $94 \%$, positive predictive value $86 \%$ ).

\section{SUBSEQUENT ASSESSMENT}

Comparison of the radiographs immediately before and after extubation for the 49 patients who required intubation showed a difference between the two in 12 patients. In nine of these 12 patients subtle changes in small air or fluid collections were present, which in no way influenced subsequent management. In two patients technical problems with the drain (subcutaneous location and lung intubation respectively) were suspected clinically and confirmed on the radiograph. In one patient, who had received assisted ventilation in the intensive care unit, the pre-extubation radiograph alerted us to the presence of an unsuspected large contralateral pneumothorax. On no occasion did removal of the drain lead to worsening of the condition for which the tube had been inserted.

Table 3 shows the accuracy of physical examination on the morning after admission in detecting progression of small air and/or fluid collections. This occurred in three patients with a haemothorax and in five with a haemopneumothorax; in each instance it was the haemothorax that increased. In seven of these eight cases the change was detected by physical examination.

\section{OUTCOME}

Of the 56 hemithoraces with a large air or fluid collection that required drainage, eight $(15 \%)$ had a large residual collection after removal of the drain; all were identified by 
Table 3 Comparison of the initial chest radiographs of patients with small air and fluid collections with the findings at the physical examination and the radiographs the day after admission

\begin{tabular}{llll}
\hline Small collections & $\begin{array}{l}\text { Initial } \\
\text { radiographic } \\
\text { diagnosis }\end{array}$ & $\begin{array}{l}\text { Radiographic } \\
\text { progression } \\
\text { to intubatable } \\
\text { lesion }\end{array}$ & $\begin{array}{l}\text { Progression } \\
\text { predicted } \\
\text { clinically }\end{array}$ \\
\hline Pneumothorax & 29 & 0 & 0 \\
Haemothorax & 13 & 3 & 3 \\
Haemopneumothorax & 21 & 5 & 4 \\
\hline
\end{tabular}

physical examination. Four patients had a second aspiration; three of these subsequently developed an empyema and required decortication.

Fifty four patients attended for follow up two weeks after discharge; they included 38 of the 49 patients who required intercostal drainage. At review four patients had a large fluid collection, which required drainage in three cases and decortication of an organised clot in one.

\section{Discussion}

There is diversity of opinion about the optimal frequency of the chest radiograph as a guide to management decisions in patients with penetrating pleural trauma. In some medical centres they have two chest radiographs within a few minutes of admission ${ }^{23}$; in others most patients will have only two chest radiographs during their entire hospital stay. ${ }^{1}$ The tendency to mistrust the stethoscope in favour of the chest radiograph in making management decisions is well illustrated by Weigelt $e t$ al. ${ }^{2}$ In their series as many as seven radiographs were obtained routinely during the first 24 hours in patients with asymptomatic chest injuries.

We do not dispute the need for a chest radiograph in the initial assessment of the patient with chest trauma. In our hospital, however, where a chest radiograph is not always available immediately in the resuscitation area, about one in 20 patients with a penetrating pleural injury required immediate pleural intubation on clinical grounds alone (because of severe respiratory distress, shock, or mediastinal shift). Our results show that this is safe in the hands of experienced clinicians provided that prior aspiration of blood or air confirms that an appreciable collection is present. This policy has been recommended elsewhere. ${ }^{4}$ In the field insertion of a tube thoracostomy may be life saving, particularly if air evacuation of casualties is necessary. ${ }^{5}$

Whereas physical examination identifies nearly all large air or fluid collections correctly, it is much less able to detect a small haemothorax or pneumothorax. These diagnostic errors, however, are seldom translated into wrong management decisions because our policy is to observe rather than intubate small collections. Thus failure of the physical examination to identify a small collection is of no practical consequence. Previous reports from our institution have shown the safety of such a policy. ${ }^{167}$ In the present series only eight of the 57 small air or fluid collections progressed in size and required intubation, and seven of these were detected by physical examination. This low progression rate supports the use of a selective intubation policy. We believe that treating all air or fluid collections by tube thoracotomy, as advocated by some authors, ${ }^{8}$ is not justified, particularly as the insertion of intercostal drains is not without complications even in experienced hands. $^{9-11}$ Simple aspiration of small pneumothoraces is not necessary as these resolve almost invariatly within 48 hours. We do not aspirate small haemothoraces because this does not appear to prevent progression to a size that requires drainage.

Our study suggests that chest radiography before removal of the intercostal drain is questionable because comparison of the radiographs taken before and after extubation revealed no clinically important differences. Removing the drain does not adversely affect lung expansion or the size of the pleural collection, and removing a non-functioning drain without prior radiography appears to be safe. In our view the main indication for obtaining a chest radiograph while the drain is still in situ is continued respiratory distress despite seemingly adequate drainage or doubts about whether the drain is in the correct position or functioning correctly. We have therefore decided to discontinue the practice of obtaining a routine chest radiograph before removing a drain that is not draining.

Armed with prior knowledge of the exact extent and nature of the original air or fluid collection and the collection remaining after extubation, we were able to identify nearly all the problems that required further management by physical examination alone. Though the yield of a predischarge chest radiograph is low, we routinely obtain one for a final assessment of outcome in patients who often do not return for outpatient review. Medicolegal considerations may dictate the need for a final inpatient radiograph.

Benefits, however, are to be balanced against costs. In a large trauma centre such as ours a policy of more detailed radiological assessment than is necessary for management decisions constitutes a considerable logistic burden on resources and does not seem to be translated into more efficient care of the patients.

In conclusion, our study shows that in penetrating chest trauma physical examination, when conducted by experienced trauma surgeons, is reliable in diagnosing large pleural collections of air and fluid at all phases of management. We believe that our policy of maximal clinical and appropriate radiological assessment is safe and effective.

1 Muckart DJJ, Luvuno FM, Baker LW. Penetrating injuries of the pleural cavity. Thorax 1984;39:789-93.

2 Weigelt JA, Aurbakken CM, Meier DE, et al. Management of asymptomatic patients following stab wounds to the chest. J Trauma 1982;22:291-3. 
3 Ordog GJ, Balasubramanuim S, Wasserberger J. Outpatient management of 357 gunshot wounds of the chest. $J$ Trauma $1983 ; 23: 832-5$.

4 Lewis FR. Thoracic trauma. Surg Clin N Am 1982;62: 97-104.

5 Zakharia AT. Cardiovascular and thoracic battle injuries in the Lebanon war. J Thorac Cardiovasc Surg 1985;89: 723-33.

6 Hegarty MM. A conservative approach to penetrating injuries of the chest. Experience with 131 successive cases. Injury 1976;8:53-9.

7 Muckart DJJ. Delayed pneumothorax and haemothorax following observation for stab wounds of the chest. Injury
1985;16:247-8.

8 Oparah SS, Mandal AK. Penetrating stab wounds of the chest experience with 200 consecutive cases. J Trauma chest experience with 200 consecutive cases. J Trauma

9 Hirshberg A, Thomson SR, Bade PG, Huizinga WKJ. Pitfalls in the management of penetrating chest trauma. Am J Surg 1989;157:372-5.

10 Millikan JS, Moore EE, Steiner E. Complications of tube thoracostomy for acute trauma. Am J Surg 1980;140: $738-41$.

11 Eriksson A. Fatal iatrogenic exsanguination from pleural drain insertion into the inferior cava. Thorac Cardiovasc Surg 1982;30:191-3. 